\title{
Serotonergic Agents and Alcoholism Treatment: A Simulation
}

\author{
Scott F. Stoltenberg
}

\begin{abstract}
Background: Those with early-onset alcoholism may better respond to ondansetron (a 5-HT 3 receptor antagonist) than to selective serotonin reuptake inhibitor (SSRI) treatment, whereas those with late-onset alcoholism may present the reverse response pattern. Johnson and colleagues proposed a model that attempts to explain the observed treatment response patterns of those with early and late alcoholism onset by focusing on the influence of a common genetic variant in the serotonin transporter regulatory region (5-HTTLPR) on serotonin (5-HT) and dopamine (DA) system function.

Methods: The present study formalizes and extends Johnson's descriptive model into a computer simulation consisting of differential equations. For each of 16 conditions defined by genotype, drinking status, diagnostic status, and drug treatment, data were generated by 100 simulation runs.

Results: In every condition, the S/_genotype (S/S and S/L) had higher extracellular 5-HT levels than did the $\mathrm{L} / \mathrm{L}$ genotype. The $\mathrm{S} /$ genotype also had higher rates of postsynaptic DA firing than did the $\mathrm{L} / \mathrm{L}$ genotype with the exception of the SSRI treatment condition, where the firing rates were similar. Drinking generally increased levels of extracellular 5-HT, reduced rates of presynaptic 5-HT firing, and increased rates of postsynaptic DA firing. Drinking produced increases in DA activation that were greater for the L/L genotype in the SSRI treatment condition and for the S/_genotype in the ondansetron treatment condition.

Conclusions: Genotype at 5-HTTLPR may influence relative reward of drinking alcohol while a person is under pharmacological treatment for alcoholism. Alternatively, 5-HTTLPR genotype may influence pathways of alcohol craving. Clinical studies should examine these hypotheses.
\end{abstract}

Key Words: Computational Model, Serotonin Transporter, 5-HT 3 Receptor, SSRI, Ondansetron.

$\mathbf{W}$ HY DO SOME patients respond to one type of alcoholism treatment but not to another? Are there patient characteristics, such as age of onset or a particular genotype, that are useful predictors of alcoholism treatment response? These important questions remain to be answered.

To provide a framework for understanding differential response of early- and late-onset alcoholism subtypes to treatment with selective serotonin reuptake inhibitors (SSRIs) and ondansetron (5- $\mathrm{HT}_{3}$ receptor antagonist), Johnson and colleagues presented a theoretical model that incorporated recent empirical findings and our current understanding of serotonergic (5-HT) function (Johnson, 2000; Johnson and Ait-Daoud, 2000). This sophisticated descriptive model represents an important step in conceptualizing the ways in which genetic variation for a component in a neurotransmitter system may affect alcoholism phenotypes, in this case treatment response, taking into account the effects of

From the University of Michigan, Department of Psychiatry, Addiction Research Center, Ann Arbor, Michigan.

Received for publication April 14, 2003; accepted September 1, 2003.

Supported by Grant K01 AA00295 from NIAAA.

Reprint requests: Scott F. Stoltenberg, PhD, University of Michigan, Department of Psychiatry, Addiction Research Center, 400 E. Eisenhower Parkway, Suite 2A, Ann Arbor, MI 48108; Fax: 734-615-6085; E-mail: sstolten@umich.edu.

Copyright (C) 2003 by the Research Society on Alcoholism.

DOI: 10.1097/01.ALC.0000098876.94384.0A both acute and chronic alcohol exposure and neurotransmitter system regulatory mechanisms.

The model presented by Johnson and colleagues hypothesizes that functional changes in the dopamine (DA) system that are an adaptation to genetic or alcohol-induced changes in 5-HT function explain why ondansetron seems to be an effective alcoholism treatment for those with early-onset but not for those with late-onset alcoholism. This argument assumes that the L/L genotype at the 5-HT transporter promoter (5-HTTLPR) is more prevalent in those with early-onset alcoholism. In the present study, whether the $\mathrm{L} / \mathrm{L}$ genotype is associated with early-onset alcoholism is not addressed. Because the Johnson model is based on a comparison of two functionally different 5-HTTLPR genotypes, the genotype is the primary grouping category in this study, and issues of alcoholism subtype will be ignored for simplicity.

The main hypothesis generated by the model is that alcohol consumption (both chronic and acute) is more rewarding (via DA activity) for those with the 5-HTTLPR L/L genotype because their dopaminergic neurons possess larger populations of $5-\mathrm{HT}_{3}$ receptors as a result of up-regulation in response to low 5-HT levels. Treatment with ondansetron blocks DA activation mediated through $5-\mathrm{HT}_{3}$ receptors, thereby reducing the rewarding effects of drinking. 
The present study implements Johnson's model by using a system dynamic computer simulation to examine whether the predictions made by the descriptive model are supported by a more rigorous and quantitative model construction. Extensions to the model are proposed that will facilitate the exploration of other pharmacological treatments for alcoholism and of the effects of other genetic variants in the serotonergic neurotransmitter system.

\section{METHODS}

Because system dynamic computer simulations are well suited to model biological control systems with more precision than a descriptive model (Gallaher, 1996), this report details a system dynamics version of the Johnson model. System dynamics is descended from earlier work in cybernetics (Wiener, 1961) and general systems theory (von Bertalanffy, 1968) regarding feedback and the flow of information in systems. Computer simulation can facilitate the generation of testable hypotheses when the input is complicated and when feedback loops are present and may enable the identification of leverage points by which large changes in system behavior can result from small inputs (Axelrod, 1997; Gallaher, 1996).

\section{Software}

This model is an extension of a presynaptic regulatory model of 5-HT function (S. F. Stoltenberg, unpublished data, 2003) implemented using STELLA ${ }^{\circledR}$ Research 6.0 for Windows (Chichalkly et al., 2000), a commercially available simulation tool. The simulation runs by iteratively solving differential equations. Simulation data were generated using Berkeley Madonna 8.0.1 (Zahnley, 2000) for batch runs.

\section{Equations}

The following calculations were performed 100 times for each of 500 time steps (i.e., $\mathrm{dt}=0.01$ ) for a total of 50,000 calculations per simulation run.

The change in extracellular 5-HT (dS/dt) was determined by the rate of 5-HT flowing out of extracellular space $(\mathrm{O})$ and the rate flowing in (I).

$$
\mathrm{dS} / \mathrm{dt}=-\mathrm{O}+\mathrm{I}
$$

\section{Input Variables}

We defined inhibitory thresholds (ITs) as the amount of extracellular 5-HT above which presynaptic 5-HT neural firing is inhibited. That is, IT represents the level of somatodendritic autoreceptor sensitivity. Initial IT values were set below the level of the average release value because it was reasoned that firing should be inhibited if the amount of 5-HT remaining in the extracellular space was equal to or greater than the average release amount. The assumption is that for proper neurotransmission, a substantial amount of neurotransmitter must be cleared from the extracellular space before another firing event is permitted to occur.

When the amount of extracellular 5-HT was below the inhibitory threshold, 100 units of 5-HT was released (R), simulating vesicular release that results from an action potential (i.e., presynaptic neuron firing event). The release value is rather arbitrary at this level of abstraction because the important issue here is how these variables relate to one another, not whether the parameter values are better suited to mice or humans. Direct application of this model to any specific empirical situation runs the risk of drawing attention away from the underlying system dynamics.

In the present negative feedback model, presynaptic vesicular release was inhibited when the level of extracellular 5-HT was greater than the IT. In the absence of vesicular release, transporter-mediated efflux was simulated, referred to here as "leakage" (L). Transporter-mediated efflux is known to occur through monoamine transporters, including serotonin transporter (SERT) (Johnson et al., 1998; Scholze et al., 2000), although details of transporter-mediated release in vivo are not well understood. To simulate transporter-mediated release in the present model, a new value for $\mathrm{L}$ was chosen at random from a normal distribution with mean $\mathrm{R} / 20$ (i.e., $5 \%$ of vesicular release) and variance of $\mathrm{L} / 10$ at each time step.

$$
\text { if }[S]_{t}<\text { IT then } I_{t}=R \text { else } I_{t}=L
$$

The amount of 5-HT removed from extracellular space $\left(\mathrm{O}_{\mathrm{t}}\right)$ was modeled as a function of the extracellular clearance rate (CR) rate multiplied by the amount of extracellular 5-HT.

$$
\mathrm{O}_{\mathrm{t}}=\mathrm{CR} *\left[\mathrm{~S}_{\mathrm{t}}\right]
$$

Clearance rate variation mediated by the SERT may be genetic in origin (e.g., 5-HTTLPR genotype; Lesch et al., 1996) and altered by pharmacological agents (e.g., SSRI). In the present simulation, the clearance rate (i.e., SERT function) was modeled as a function of the 5-HTTLPR genotype (Lesch et al., 1996), chronic alcoholism (Heinz et al., 2000), and SSRI treatment condition (Meyer et al., 2001).

Postsynaptic DA firing was modeled as a binomial variable (i.e., $0=$ no fire, 1 = fire) with probability based on the amount of extracellular 5-HT. Specifically, at each time step, the probability of DA firing (DAprob) was binomial with $p=\left[S_{t}\right] / 500$, which produced DA firing probabilities that were proportional to extracellular 5-HT concentration and provided DA firing rates with adequate range across test conditions. The potentiation of $5-\mathrm{HT}_{3}$ receptors resulting from low extracellular 5-HT level was modeled by increasing the probability of DA firing when extracellular 5-HT levels were below the standard release value (i.e., 100). In that case, the probability of DA firing was increased in inverse proportion to the level of extracellular 5-HT (i.e., DAprob + $\left.\left(1 /\left[\mathrm{S}_{\mathrm{t}}\right]\right)\right)$.

Random numbers were drawn from normal distributions with means and variances specified using a lagged Fibonacci generator with a period of approximately $10^{84}$ (Zahnley, 2000) for initial serotonin, release, and leakage values. Random number seeds varied for each calculation.

\section{Model Dynamics}

To capture the progressive desensitization that occurs for somatodendritic 5-HT autoreceptors, a simple dynamic rule to adjust inhibitory threshold was implemented. At each time step, the model evaluated whether the system had fired. If the system had not fired (i.e., was inhibited by somatodendritic autoreceptors indicating high levels of 5-HT), the IT was increased, which increased the likelihood that the system would fire at the next time step. Alternatively, if the system had fired, the IT was decreased, which reduced the likelihood that the system would fire at the next time step. The levels of IT adjustments were represented by the variables ITUP and ITDOWN. Adjustment values were set at $3 \%$ of the initial release value (i.e., $3 \%$ of $100=3$ ).

Another dynamic rule was used to regulate the amount of 5-HT released, which models the effect of the presynaptic terminal 5-HT autoreceptor $\left(5-\mathrm{HT}_{1 \mathrm{~B}}\right)$. The standard level of release (i.e., 100 units) was used when extracellular 5-HT level was between 50 and 150 . When the level of extracellular 5-HT was low (i.e., below 50), more 5-HT was released (150 units). Alternatively, when the level of extracellular 5-HT was high (i.e., above 150 ), less 5 -HT was released (50 units).

\section{Outcome Measures}

Level of extracellular 5-HT was one of the main outcome variables of interest. For each run of the simulation, the initial starting level of 5-HT was set at 50 . The other main outcome variables were 5-HT and DA firing rates defined as the number of times that a system fired (i.e., released 5-HT, or activated the postsynaptic DA system) in 500 time steps. For each model condition, the mean for 100 simulation runs was recorded for extracellular 5-HT level and cumulative 5-HT and DA firing rates for 500 time steps. 


\section{No Alcoholism}

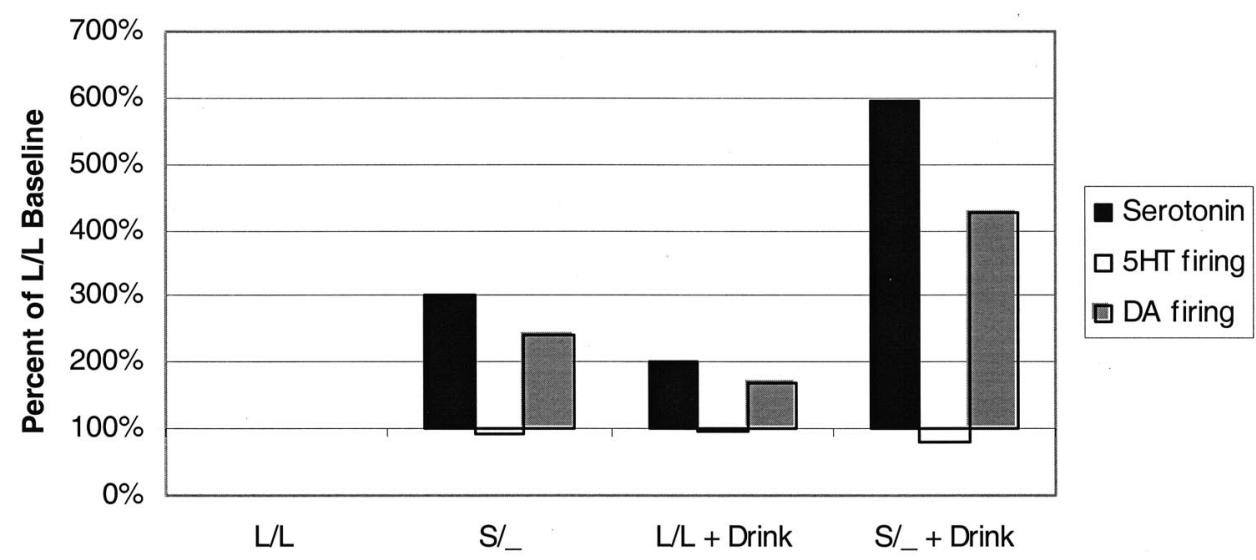

Fig. 1. Mean extracellular 5-HT level, presynaptic 5-HT firing, and postsynaptic dopaminergic firing for 5-HTTLPR S/_ and L/L genotypes without ethanol drinking

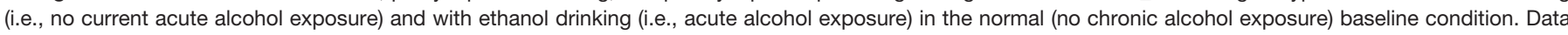
presented are percent change from the baseline L/L genotype. No bars are shown for the L/L genotype because values are set at $100 \%$.

\section{Test Conditions}

Serotonin Transporter Genotype. The values for transporter genotype were based on the 5-HTTLPR empirical literature, which indicates that the $\mathrm{L} / \mathrm{L}$ genotype has 2- to 3-fold higher activity than either the $\mathrm{S} / \mathrm{L}$ or $\mathrm{S} / \mathrm{S}$ genotype (Lesch et al., 1996). In the present simulation, the value of the $\mathrm{L} / \mathrm{L}$ genotype was set at 0.90 and the $\mathrm{S} /$ _ genotype at 0.30 . As a result, at any level of extracellular $5-\mathrm{HT}$, the $\mathrm{L} / \mathrm{L}$ genotype would remove $90 \%$, whereas the S/_ genotype would remove $30 \%$.

Drinking. Acute alcohol exposure has been shown to increase the amount of 5-HT released per action potential by about $200 \%$ of baseline in the nucleus accumbens of rats after ethanol injection (Yan and Lewander, 1999). In the drinking conditions tested in the present simulation, we doubled the amount of 5-HT released from the standard level of 100 to a random number selected from a normal distribution with mean 200 and variance 20 . This condition represents acute alcohol exposure. No distinctions were made regarding social drinking history.

Chronic Alcohol Exposure. Transporter function has been shown to be reduced in alcoholic individuals with the $\mathrm{L} / \mathrm{L}$ but not in those with $\mathrm{S} /$ 5-HTTLPR genotype (Little et al., 1998). In this simulation, we examined 5-HT level, 5-HT, and DA firing rates in the L/L genotype with chronic alcoholism (i.e., a history of chronic alcohol exposure) by reducing transporter function to 0.495 (i.e., $0.90 \times 0.55$ ). We did not reduce transporter functioning in the $\mathrm{S} /$ _ genotypes in the chronic alcoholism condition to be consistent with empirical results (Heinz et al., 2000). No distinctions were made regarding family history of alcoholism.

SSRI Treatment. SSRIs block reuptake of 5-HT from extracellular space via the SERT. At therapeutic SSRI doses for depression, availability of SERT is reduced relative to baseline by approximately $80 \%$ (Meyer et al., 2001). In the SSRI condition of the present simulation, we reduced transporter function to $20 \%$ of the baseline for that genotype.

Ondansetron Treatment. Ondansetron is a $5-\mathrm{HT}_{3}$ antagonist (i.e., blocker). In the context of this simulation, the presence of ondansetron reduced by one half the probability of postsynaptic DA firing. Specifically, in the ondansetron condition, the probability of DA firing was based on the binomial with probability $p=\left[S_{t}\right] / 1000$.

\section{Data Analysis and Statistics}

The level of extracellular 5-HT reported represents the serotonin value at the end of a simulation run (i.e., step 500) averaged over 100 runs. The serotonin and dopamine firing rates are the cumulative firing rates at step 500 averaged over 100 runs of the simulation. Values are expressed as percentages of the $\mathrm{L} / \mathrm{L}$ genotype baseline (i.e., no alcoholism, no drinking) levels. Confidence intervals around estimates of means are exceedingly small because each value represents a mean of 100 runs. For mean extracellular 5-HT level, the largest standard deviation obtained was \pm 0.71 in the LASD (L/L genotype, chronic alcoholism, SSRI treatment, drinking) condition. For mean presynaptic 5-HT firing rate, the largest SD was \pm 0.26 in the $\mathrm{L}(\mathrm{L} / \mathrm{L}$ genotype, no drinking, baseline) condition. For mean DA firing rate, the largest SD obtained was \pm 1.14 in the SA (S/ genotype, chronic alcoholism, no drinking) condition. Data are presented in Figs. 1 and 2 as percent change from the $\mathrm{L} / \mathrm{L}$ genotype baseline condition, that is, with no drinking, no chronic alcoholism, and no treatment. Differences greater than $5 \%$ can be considered statistically significant at $\alpha_{2}=0.01$ (Cohen, 1988).

\section{RESULTS}

\section{No Alcoholism}

This is the baseline condition of the model. The mean extracellular 5-HT level for the S/_genotype was 300\% that of the $\mathrm{L} / \mathrm{L}$ genotype in the no-drinking condition (see Fig. 1). Drinking increased 5-HT level for both genotypes with a greater relative increase for the $\mathrm{S} /$ genotype $(+295 \%$ versus $+100 \%$ for $\mathrm{L} / \mathrm{L})$. The mean presynaptic 5-HT firing rate for the S/ genotype was $92 \%$ that of the $\mathrm{L} / \mathrm{L}$ genotype. Drinking decreased the mean presynaptic 5 -HT firing rate for S/ $(-11 \%)$ but not for the $\mathrm{L} / \mathrm{L}$ genotype $(-4 \%)$. The mean postsynaptic DA firing rate in the no-drinking condition for the $\mathrm{S} /$ genotype was $242 \%$ that of the $\mathrm{L} / \mathrm{L}$ genotype. Drinking increased the postsynaptic DA firing rate for both genotypes; however, the relative increase was greater for the S/_ (+186\%) genotype than for the L/L (+69\%) genotype. Baseline simulation conditions resulted in differences among 5-HTTLPR genotypes in extracellular 5-HT level, presynaptic 5-HT, and postsynaptic DA firing rates. As predicted in the Johnson model, the $\mathrm{L} / \mathrm{L}$ genotype was associated with lower extracellular 5-HT levels and lower postsynaptic DA firing rates than the S/ genotype. For both genotypes, drinking increased 5-HT 

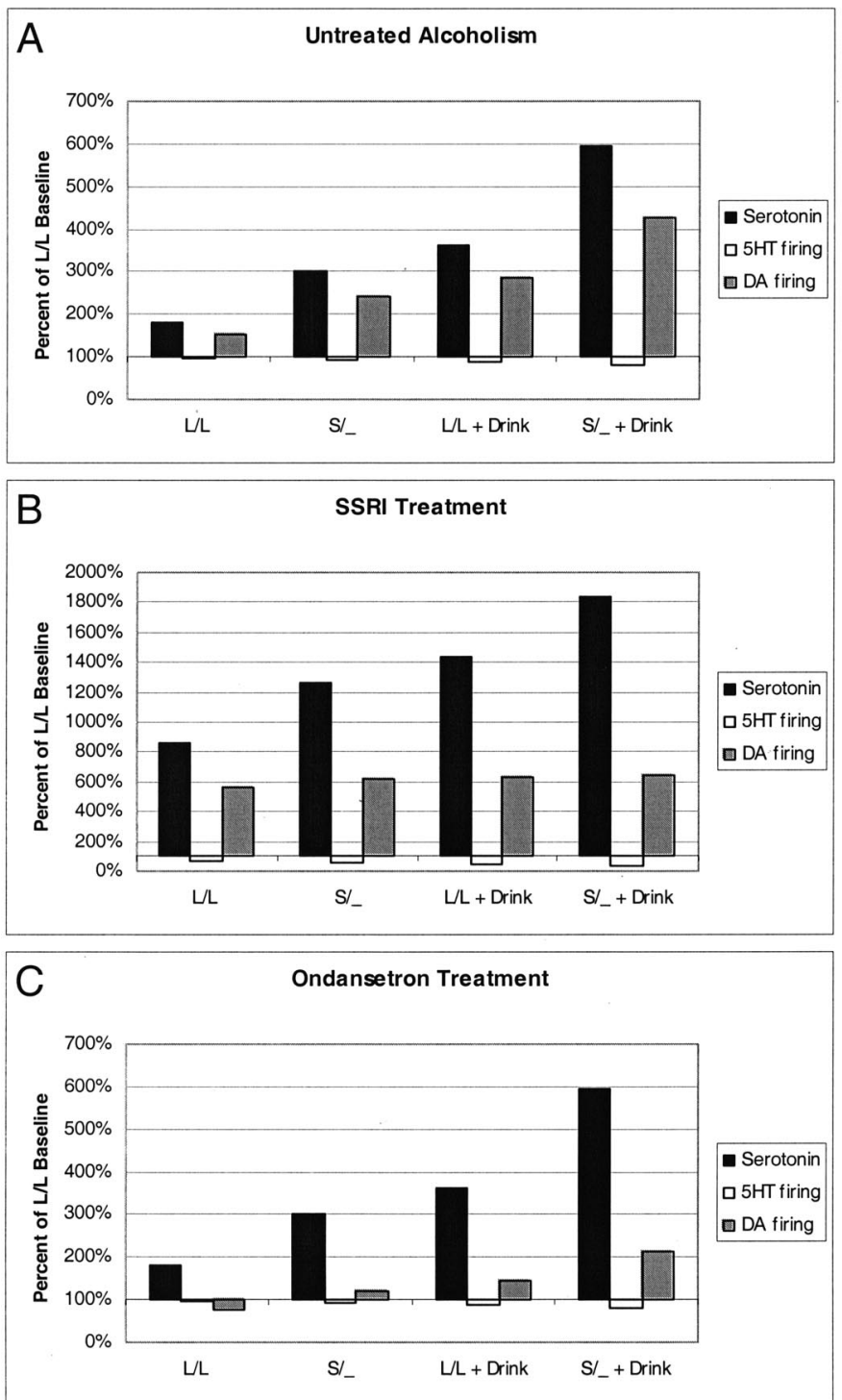

Fig. 2. Mean extracellular 5-HT level, presynaptic 5-HT firing, and postsynaptic dopaminergic firing for 5-HTTLPR S/_ and L/L genotypes with alcoholism (i.e., chronic alcohol exposure), without and with drinking (i.e., acute alcohol exposure) for (A) untreated alcoholism, (B) alcoholism treated with SSRI, and (C) alcoholism treated with ondansetron. Alcoholism is defined as chronic alcohol exposure in this study. Data presented are percent change from the L/L genotype no alcoholism baseline condition. Note that the $y$ axis for panel $B$ is not the same as the others.

level and postsynaptic DA firing rate while it decreased presynaptic 5-HT firing rates. Contrary to prediction, acute ethanol exposure (i.e., drinking) induced increases in DA activation that were greater for the $\mathrm{S} /$ - $_{\text {than }}$ for the $\mathrm{L} / \mathrm{L}$ genotype.

\section{Untreated Chronic Alcoholism}

In the no-drinking condition of untreated chronic alcoholism, mean extracellular 5-HT level for the S/_genotype was higher ( $300 \%$ of $\mathrm{L} / \mathrm{L}$ baseline) than that of the $\mathrm{L} / \mathrm{L}$ genotype (182\% of L/L baseline; see Fig. 2A). In addition to the effect of untreated chronic alcoholism, drinking further raised the mean 5-HT levels for both genotypes (S/ $=+295 \% ; \mathrm{L} / \mathrm{L}=+181 \%)$. In the no-drinking condition of untreated chronic alcoholism, presynaptic 5-HT firing rates for the $\mathrm{L} / \mathrm{L}$ genotype were essentially unchanged (97\%) relative to the $\mathrm{L} / \mathrm{L}$ genotype at baseline, whereas those for the S/_ genotype were slightly reduced $(92 \%)$. In addition to the effect of untreated chronic alcoholism, drinking further decreased mean rates of presynaptic 5-HT firing in the $\mathrm{L} / \mathrm{L}(-7 \%)$ and the $\mathrm{S} /$ genotypes $(-11 \%)$. The mean postsynaptic DA firing rate for the S/_ genotype (242\% of $\mathrm{L} / \mathrm{L}$ baseline) was greater than for the $\mathrm{L} / \mathrm{L}$ genotype $(155 \%$ of $\mathrm{L} / \mathrm{L}$ baseline) in the no-drinking condition. Drinking further raised postsynaptic DA firing rates for both genotypes with a greater relative increase for the S/_ $(+186 \%)$ than for the $\mathrm{L} / \mathrm{L}$ genotype $(+131 \%)$. Genotype differences in both extracellular 5-HT level and postsynaptic DA firing rate were observed in the untreated alcoholism condition, and although the differences were in the same direction as observed in the no-alcoholism baseline condition, they were less pronounced. Drinking increased the level of extracellular 5-HT, increased postsynaptic DA firing rate, and decreased presynaptic 5-HT firing rates. Contrary to prediction, chronic ethanol exposure (i.e., alcoholism) induced increases in DA activation that were greater for the S/ than for the $\mathrm{L} / \mathrm{L}$ genotype.

\section{Chronic Alcoholism Treated with SSRI}

Data generated in the SSRI treatment condition were compared with those generated in the untreated alcoholism condition to assess the effect of SSRI alcoholism treatment. The increase in mean extracellular 5-HT level under SSRI treatment with no drinking relative to the untreated alcoholism no-drinking condition was greater for the S/_genotype $(+962 \%)$ than for the L/L genotype (683\%; see Fig. 2B). Drinking raised the extracellular 5-HT levels for the two genotypes equally $\left(\mathrm{S} /{ }_{-}=+574 \%\right.$; $\left.\mathrm{L} / \mathrm{L}=+572 \%\right)$ relative to the SSRI condition with no drinking. In the no-drinking SSRI condition, rates of presynaptic 5-HT firing decreased for both genotypes $\left(\mathrm{L} / \mathrm{L}=-27 \%, \mathrm{~S} /{ }_{-}=\right.$ $-37 \%$ ) relative to the untreated alcoholism no-drinking condition. Drinking in the SSRI treatment condition produced a further decrease in the presynaptic 5-HT firing rate for both genotypes $(\mathrm{L} / \mathrm{L}=-22 \%, \mathrm{~S} /=-23 \%)$ relative to the SSRI condition with no drinking. Mean rates of postsynaptic DA firing were elevated for both genotypes in the SSRI no-drinking condition relative to the chronic alcoholism no-drinking condition $(\mathrm{L} / \mathrm{L}=+408 \%$; S/_ $=$ $+378 \%$ ). Drinking raised the postsynaptic DA firing rates for both genotypes with a larger increase in the L/L group $\left(\mathrm{L} / \mathrm{L}=+69 \% ; \mathrm{S} /{ }_{-}=+24 \%\right)$ relative to the SSRI condition with no drinking. During SSRI alcoholism treatment, 5-HT level increased for both genotypes relative to the untreated condition. SSRI treatment reduced rates of presynaptic 5-HT firing and increased rates of postsynaptic DA firing for both genotypes. For both genotypes, SSRI treatment 
condition produced the highest levels of extracellular 5-HT, the highest postsynaptic DA firing rates, and the lowest presynaptic 5-HT firing rates achieved in any test condition.

\section{Chronic Alcoholism Treated With Ondansetron}

For both genotypes, the pattern of results for extracellular 5-HT level and for presynaptic 5-HT firing rate in the ondansetron treatment condition was identical to the pattern observed in the untreated alcoholism condition (Fig. $2 \mathrm{C})$. In this simulation, ondansetron treatment was modeled to influence postsynaptic DA firing rate and did not affect presynaptic 5-HT function. Postsynaptic DA firing rate in the ondansetron no-drinking condition was reduced for both genotypes relative to the untreated alcoholism condition $\left(\mathrm{S} /{ }_{-}=-121 \% ; \mathrm{L} / \mathrm{L}=-77 \%\right)$. Drinking increased postsynaptic DA firing rates for both genotypes $\left(\mathrm{S} /{ }_{-}=+94 \% ; \mathrm{L} / \mathrm{L}=+65 \%\right)$ relative to the ondansetron condition with no drinking. For both genotypes, ondansetron treatment decreased postsynaptic DA firing relative to the untreated alcoholism condition. In fact, postsynaptic DA firing rates for the no-drinking ondansetron condition were below rates for the no-alcoholism L/L genotype baseline. Drinking increased postsynaptic DA firing rates for both genotypes, with a greater rate of increase observed in the S/_ genotype; however, rates remained substantially lower than those observed in the untreated alcoholism drinking condition.

\section{DISCUSSION}

The results of this simulation are largely consistent with the descriptive model presented by Johnson and colleagues (Johnson, 2000; Johnson and Ait-Daoud, 2000). The L/L genotype of the 5-HTTLPR variant was associated with lower extracellular 5-HT level and postsynaptic DA firing rates but slightly higher presynaptic 5-HT firing rates than the S/_ genotype. Changes in the pattern of simulated presynaptic 5-HT function and postsynaptic DA activation were in the same direction for both genotypes but of different magnitude.

Both acute (i.e., drinking) and chronic (i.e., alcoholism) alcohol exposure induced increases in DA activation that were greater in the $\mathrm{S} /$ _ than the $\mathrm{L} / \mathrm{L}$ genotype. However, drinking produced increases in postsynaptic DA firing that for the $\mathrm{L} / \mathrm{L}$ genotype were greater in the SSRI treatment condition and that for the S/_ genotype were greater in the ondansetron treatment condition. If DA activation is considered rewarding, drinking is more rewarding for those with the L/L genotype under SSRI than ondansetron treatment. For those with the S/_genotype, drinking is more rewarding under ondansetron than SSRI treatment.

Another potential explanation of 5-HTTLPR genotype differences in treatment response is to hypothesize that the genotypes are associated with different pathways of alcohol craving (Verheul et al., 1999).
The present simulation results suggest that individuals with the L/L genotype may experience "reward craving" mediated via dopaminergic activation. Ondansetron treatment, which reduces DA activation via $5-\mathrm{HT}_{3}$ receptor antagonism, has been shown to be effective in individuals with early-onset alcoholism, which often is associated with binge drinking, family history of alcoholism, and inability to abstain. These characteristics define the "dopaminergic/ opiodergic dysregulation" pathway in a model of alcohol craving (Verheul et al., 1999). Such DA system dysregulation actually may be an indirect result of genetic variation that influences presynaptic 5-HT function, as demonstrated in the present study.

In the context of the present simulation, reward craving may be indexed by the postsynaptic DA firing rate in the no-drinking condition. The DA-mediated reward may be indexed as the difference between the DA firing rate in the drinking versus no-drinking conditions. For those with the $\mathrm{L} / \mathrm{L}$ genotype, ondansetron treatment reduces both craving and reward (Fig. 2C).

Simulation results suggest that individuals with the S/ genotype may experience "relief craving." Both alcohol drinking and SSRI treatment raise extracellular 5-HT levels and decrease firing rates of 5-HT neurons, and both are used to treat negative affect (i.e., anxiety and depression; alcohol via self-medication and SSRI via prescription), which is consistent with the relief craving pathway model mediated by GABAergic/glutamatergic dysregulation (Verheul et al., 1999). Both $\gamma$-aminobutyric acid and glutamate are known to influence 5-HT neurons in midbrain raphe nuclei (Adell et al., 2002; Tao and Auerbach, 2003), and perhaps it is through these interactions that the effect of the 5-HTTLPR genotype is manifest. For those with the S/ genotype, SSRI treatment may raise extracellular 5-HT levels into some target range and eliminate, or reduce, the urge to raise 5-HT by drinking. Moreover, it may be that for those with the S/_ genotype, drinking while under SSRI treatment elevates extracellular 5-HT level excessively.

Johnson (2000) suggested that for those with the S/ genotype, chronic SSRI treatment would produce a "modest facilitation of 5-HT neurotransmission and long-term inhibition of dopaminergic activity, thereby offsetting alcohol's rewarding effects during chronic drinking." The current simulation does not include a mechanism for desensitization of $5-\mathrm{HT}_{3}$ receptors due to chronic high levels of 5-HT. The inclusion of such a mechanism may result in a better fit with this particular hypothesis.

The results of the present simulation suggest that those with the S/_ genotype may be sensitive to extracellular 5-HT levels but insensitive to reward via DA activation and that those with the $\mathrm{L} / \mathrm{L}$ genotype may be insensitive to extracellular 5-HT levels but sensitive to DA-mediated reward, which is consistent with the craving pathway model (Verheul et al., 1999).

Interestingly, the craving pathway model identifies an "obsessive craving" pathway that is hypothesized to be 
mediated via "serotonergic dysregulation." The present simulation results suggest that the three craving pathways could all be, either indirectly or directly, influenced by serotonergic regulation. The obsessive craving pathway could be associated with differences in 5-HT metabolism or with terminal autoreceptors, each of which has been implicated in antisocial alcoholism traits in humans (Hill et al., 2002; Lappalainen et al., 1998) and in aggression and drinking in mice (Cases et al., 1995; Crabbe et al., 1996). We did not test these hypotheses in the present study.

The results of this simple dynamic model should not be interpreted to suggest that a common polymorphism in the 5-HT transporter causes alcoholism. It is generally accepted that alcoholism is a complex disorder that is the result of the coaction of multiple genes and multiple environmental risk factors. Computer simulations make it possible to study multifactorial problems with relative ease and facilitate hypothesis generation (Casti, 1997). The use of computer simulations to study heredity-behavior relations can be referred to as computational behavior genetic analysis.

The results of the present simulation are consistent with a craving pathway model (Verheul et al., 1999) and a model of alcoholism treatment (Johnson, 2000; Johnson and AitDaoud, 2000) and with empirical observations (Johnson et al., 2002). Simulation results highlight opportunities to test hypotheses in humans concerning 5-HTTLPR genotype and craving and in rodents concerning 5-HT and DA function using microdialysis and electrophysiological measures. In addition, by varying inhibitory threshold and release parameters, this model can be used to explore the potential effects of $5-\mathrm{HT}_{1 \mathrm{~A}}$ and $5-\mathrm{HT}_{1 \mathrm{~B}}$ receptor antagonists and agonists alone and in combinations with SSRI and ondansetron.

A limitation to this model is that it does not include parameters to account for differences in 5-HT synthesis, metabolism, and other postsynaptic effects that may play important roles in 5-HT regulation and function. In addition, it is difficult to measure the 5-HT and DA outcomes in humans, which makes predictions rather difficult to directly test in humans. And although the 5-HTTLPR promoter variant is one of the most studied candidate genes in psychiatric genetics (Stoltenberg and Burmeister, 2000), its effects on synaptic 5-HT levels and other aspects of neurotransmission are not well defined. On the other hand, interactions among SERT and 5- $\mathrm{HT}_{1 \mathrm{~B}}$ autoreceptors have been shown, such as $5-\mathrm{HT}_{1 \mathrm{~B}}$-mediated increases in SERT activity (Daws et al., 2000), but have not been accounted for in the present study. In addition, the effects of chronic ethanol exposure on $5-\mathrm{HT}_{3}$ receptors have not been addressed in the simulation, which may help to explain why the hypothesized pattern of DA activation (i.e., L/L > S/_) was not observed. It remains to be seen whether these limitations affect the model's capacity for improving understanding of the 5-HT system.

\section{CONCLUSION}

The results of this simulation suggest that 5-HTTLPR genotype may influence relative reward of drinking alcohol while a person is under pharmacological treatment for alcoholism. Alternatively, those with the S/_ genotype of the serotonin transporter promoter variant 5-HTTLPR may drink to increase extracellular 5-HT levels, and those with the $\mathrm{L} / \mathrm{L}$ genotype may drink to increase rates of postsynaptic dopaminergic neural firing. For the most part, the results of this simulation are in line with the predictions of the Johnson model. This study demonstrates how a computational behavior genetic analysis approach can be used to rigorously and quantitatively examine descriptive theoretical models and to generate testable hypotheses.

\section{ACKNOWLEDGMENTS}

I thank Kirk Brower, Shlomo Dellal, Srijan Sen, and two anonymous reviewers for helpful and encouraging comments on earlier versions of this manuscript.

\section{REFERENCES}

Adell A, Celada P, Abellan MT, Artigas F (2002) Origin and functional role of the extracellular serotonin in the midbrain raphe nuclei. Brain Res Brain Res Rev 39:154-180.

Axelrod R (1997) Advancing the art of simulation in the social sciences. Complexity 3:16-22.

Cases O, Seif I, Grimsby J, Gaspar P, Chen K, Pournin S, Muller U, Aguet M, Babinet C, Shih JC, et al. (1995) Aggressive behavior and altered amounts of brain serotonin and norepinephrine in mice lacking MAOA. Science (Wash. DC) 268:1763-1766.

Casti JL (1997) Would-be worlds: How simulation is changing the frontiers of science. John Wiley \& Sons, Inc. New York, NY.

Chichalkly M, Lloyd D, Hulbert L, Merritt J, Trussell R, Wallis J (2000) STELLA Research. High Performance Systems, Inc., Hanover, NH.

Cohen J (1988) Statistical Power Analysis for the Behavioral Sciences. Erlbaum, Mahwah, NJ.

Crabbe JC, Phillips TJ, Feller DJ, Hen R, Wenger CD, Lessov CN, Schafer GL (1996) Elevated alcohol consumption in null mutant mice lacking 5-HT1B serotonin receptors. Nat Genet 14:98-101.

Daws LC, Gould GG, Teicher SD, Gerhardt GA, Frazer A (2000) 5 -HT(1B) receptor-mediated regulation of serotonin clearance in rat hippocampus in vivo. J Neurochem 75:2113-2122.

Gallaher EJ (1996) Biological system dynamics: from personal discovery to universal application. Simulation 66:243-257.

Heinz A, Jones DW, Mazzanti C, Goldman D, Ragan P, Hommer D, Linnoila M, Weinberger DR (2000) A relationship between serotonin transporter genotype and in vivo protein expression and alcohol neurotoxicity. Biol Psychiatry 47:643-649.

Hill EM, Stoltenberg SF, Bullard KH, Li S, Zucker RA, Burmeister M (2002) Antisocial alcoholism and serotonin-related polymorphisms: association tests. Psychiatr Genet 12:143-153.

Johnson BA (2000) Serotonergic agents and alcoholism treatment: rebirth of the subtype concept—an hypothesis. Alcohol Clin Exp Res 24:15971601.

Johnson BA, Ait-Daoud N (2000) Neuropharmacological treatments for alcoholism: scientific basis and clinical findings. Psychopharmacology (Berl) 149:327-344.

Johnson RA, Eshleman AJ, Meyers T, Neve KA, Janowsky A (1998) $[3 \mathrm{H}]$ substrate- and cell-specific effects of uptake inhibitors on human dopamine and serotonin transporter-mediated efflux. Synapse 30:97106. 
Johnson BA, Roache JD, Ait-Daoud N, Zanca NA, Velazquez M (2002) Ondansetron reduces the craving of biologically predisposed alcoholics. Psychopharmacology (Berl) 160:408-413.

Lappalainen J, Long JC, Eggert M, Ozaki N, Robin RW, Brown GL, Naukkarinen H, Virkkunen M, Linnoila M, Goldman D (1998) Linkage of antisocial alcoholism to the serotonin 5-HT1B receptor gene in 2 populations. Arch Gen Psychiatry 55:989-994.

Lesch KP, Bengel D, Heils A, Sabol SZ, Greenberg BD, Petri S, Benjamin J, Muller CR, Hamer DH, Murphy DL (1996) Association of anxietyrelated traits with a polymorphism in the serotonin transporter gene regulatory region. Science (Wash DC) 274:1527-1531.

Little KY, McLaughlin DP, Zhang L, Livermore CS, Dalack GW, McFinton PR, DelProposto ZS, Hill E, Cassin BJ, Watson SJ, Cook EH (1998) Cocaine, ethanol, and genotype effects on human midbrain serotonin transporter binding sites and mRNA levels. Am J Psychiatry 155:207213.

Meyer JH, Wilson AA, Ginovart N, Goulding V, Hussey D, Hood K, Houle $S$ (2001) Occupancy of serotonin transporters by paroxetine and citalopram during treatment of depression: a [(11)C]DASB PET imaging study. Am J Psychiatry 158:1843-1849.
Scholze P, Zwach J, Kattinger A, Pifl C, Singer EA, Sitte HH (2000) Transporter-mediated release: a superfusion study on human embryonic kidney cells stably expressing the human serotonin transporter. J Pharmacol Exp Ther 293:870-878.

Stoltenberg SF, Burmeister M (2000) Recent progress in psychiatric genetics-some hope but no hype. Hum Mol Genet 9:927-935.

Tao R, Auerbach SB (2003) Influence of inhibitory and excitatory inputs on serotonin efflux differs in the dorsal and median raphe nuclei. Brain Res 961:109-120.

Verheul R, van den Brink W, Geerlings P (1999) A three-pathway psychobiological model of craving for alcohol. Alcohol Alcohol 34:197-222. von Bertalanffy L (1968) General Systems Theory. George Braziller. New York, New York.

Wiener N (1961) Cybernetics: Or Control and Communication in the Animal and the Machine. 2nd ed. MIT Press, Cambridge, MA.

Yan HM, Lewander T (1999) Differential tissue distribution of the enantiomers of racemic pindolol in the rat. Eur Neuropsychopharmacol 10:59-62.

Zahnley T (2000) Berkeley Madonna. Robert Macey and George Oster, Berkeley, CA. 